\title{
Palcos libertados
}

\section{Paulo Eduardo Carvalho}

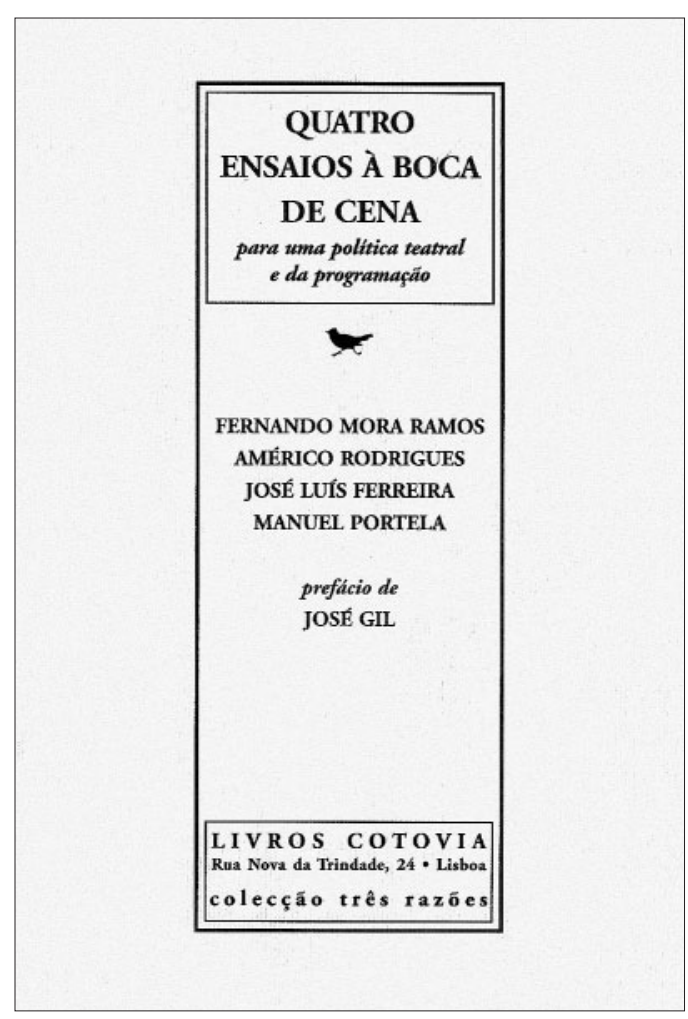

Não se pode dizer que estes Quatro ensaios à boca de cena, prefaciados por José Gil, tenham passado despercebidos: apresentados publicamente em Lisboa, Coimbra, Caldas da Rainha e Porto, respectivamente por Rui Vieira Nery, Osvaldo Manuel Silvestre, João Serra e pelo autor destas linhas, objecto de uma extensa cobertura informativa e de duas muito valorativas recensões críticas - uma nas páginas do suplemento Ípsilon, do jornal Público, e uma outra no suplemento Actual do semanário Expresso -, estas quatro reflexões Para uma política cultural e da programação têm conseguido cumprir o desígnio primeiro da visibilidade. E do mesmo modo que não haverá teatro sem público, como vaticinava António Pedro há cinco décadas atrás, também este livro não cumprirá os seus objectivos se não for lido e, mais, se não encontrar algum tipo de eco prático e concreto entre os seus leitores, mais ou menos avisados, com maior ou menor responsabilidades cívicas e políticas. Como anuncia Fernando Mora Ramos, na parte inicial da sua reflexão - que, na realidade, funciona como uma espécie de introdução a todo o volume - tratase de contribuir para "inverter a desarticulação informe e o desânimo [e] dar um sentido ao próprio futuro" ou, dito de outro modo, de "dar sentido a esta ordem ordenando-a" (pp. 22, 35).
Fernando Mora Ramos, Américo Rodrigues, José Luís Ferreira e Manuel Portela, Quatro ensaios à boca de cena: Para uma política teatral e da programação. Prefácio de José Gil. Lisboa, Livros Cotovia, 2009, 204 pp.

0 prefácio arrebatado, mas justíssimo, de José Gil, mostra-se particularmente sensivel ao "impulso crítico que anima os autores", seguro de que "este livro abrirá a oportunidade para um vasto debate, a nivel nacional, sobre o presente e o futuro do teatro no nosso pais" (pp. $9,11)$. Muito embora os autores não esclareçam a origem deste projecto, atrevo-me a sugerir que teria sido útil acrescentar uma breve nota introdutória que partilhasse com o leitor o modo como se chegou a objecto tão singular, tão raro e, reconheça-se, depois da sua leitura atenta, tão urgente.

Sem qualquer desprimor para o reconhecido percurso profissional de qualquer um dos restantes autores, este Quatro ensaios à boca de cena parece retomar a ambição repetidamente expressa por Fernando Mora Ramos quando, entre 1998 e 2000, dirigiu o projecto Teatro escrito(s): Revista de ensaio e ficção, uma iniciativa que envolvia já a editora Livros Cotovia e o então IPAE (Instituto Português das Artes do Espectáculo). Com três números subordinados aos títulos sempre ostensivamente interrogativos de "Para que serve o teatro?" (1998), "Está tudo bem com o teatro em Portugal?" (1999) e "Teatro português: 'Pera onde is?" (2000), o projecto apresentava-se, no seu primeiro editorial, no estilo muito particular de Fernando Mora Ramos, como:

\footnotetext{
[U]ma revista espalhando alimentarmente fome de autenticidade que por ai desanda, falando do pais do teatro que temos, o politico teatral e dos afectos de quem emparcela outros muitos seus, e do próprio pais, se para tal houver engenho e arte, e uma revista revelando também um teatro dos unidos em desunião, tão pouco dialéctica e objectiva e tão imensamente fadodramática e faladora, que somos, até aos cotovelos. (...) Uma revista capaz de (...) partir para a identificação do teatro português e de lhe propor caminhos ao questionar-Ihe as opções, os modos de fazer e as ausências, sem quaisquer intuitos missionários, nem terapêuticos, obviamente, antes republicanos e laicos (...). (Ramos 1998: 9, 11)
}

E nesse mesmo primeiro editorial, o autor anunciava o ambicioso conteúdo programático dos dois números seguintes, em termos que parecem reveladores da ambição que, passada mais de uma década, continua a animar este livro:

Genericamente intitulados como "Identificação de um teatro", tentarão um levantamento sintese de tudo o que compõe o teatro português, 
Teatro Nacional São 」oão, da política teatral às estruturas de produção, da descentralização à centralização, dos nacionais aos pontuais, dos orçamentos à política teatral, do vanguardismo ao teatro de rua, do cosmopolitismo ao provincianismo, dos estivais aos festivais, da dramaturgia ao teatro imagem, etc., fugindo à argumentação circular, pensamento pobre do inexistente debate no teatro português, e tentando mostrar e reflectir equilibradamente o que há e o que seria desejável como horizonte teatral futuro. (Ibidem: 12)

No editorial do terceiro e último número desta Teatro escrito(s), Fernando Mora Ramos regressaria à denúncia do "quase inexistente debate da questão teatral portuguesa" e à urgência na exploração da "problemática identitária do teatro português" (Ramos 2000: 11, 12). A necessidade então enunciada de modo imperativo, de "uma identificação da actual forma do teatro português, das fragilidades e insuficiências do seu tecido organizacional, das suas partes não visíveis" (Ramos 1999: 7), continua a ser a mesma que, muitos artigos no jornal Público e na revista Finisterro depois - e moderada uma certa tendência para o bon mot por vezes mais do que para o mot juste - conduz a diagnósticos tão penetrantes como aqueles que, nas primeiras páginas de "Teatro português: Para uma superação da insignificância", decompõem e amplificam "o informe e desalentado estado anímico do teatro em Portugal" (17) Começando por imputar responsabilidades partilhadas ao Estado e aos agentes teatrais, pela prolongada ausência de uma "política estruturada" para o teatro em Portugal o autor faz seguir este primeiro esboço do "país culinário rasteiro, incapaz de orgânica própria" (19), caracterizado por "uma extraordinária tendência abortiva ligada a uma ordinária vocação para a inércia" (22), de uma louvável tentativa de explicação da necessidade do teatro nas sociedades humanas, como condição indispensável para justificar, depois, a apresentação de um "conjunto de medidas articulado, integrado e coordenado dinamicamente" (17)

Com exemplos que devem mais ao domínio da dramaturgia - e poderia ter sido interessante ampliá-los a outras manifestações mais especificamente cénicas e teatrais -, afirma-se sobretudo o "potencial polémico e cívico" do teatro (20), a sua capacidade de agir "contra o esquecimento, a indiferença, a ocultação do real e as práticas do segredo" e de sondar a "história humana por antecipação" (21), um pensamento resumido numa sintese eloquente:

[0 teatro] tem esse condão único, de ser o espaço que envolvendo uns e outros na mesma caixa acústica e expondo a vida nua a um olhar (des)prevenido, contém um antidoto para a demagogia,

imprevisibilidade poética, experiência cognitiva e emoção profunda, emergência do pensável que liberta. 0 teatro permite uma espécie

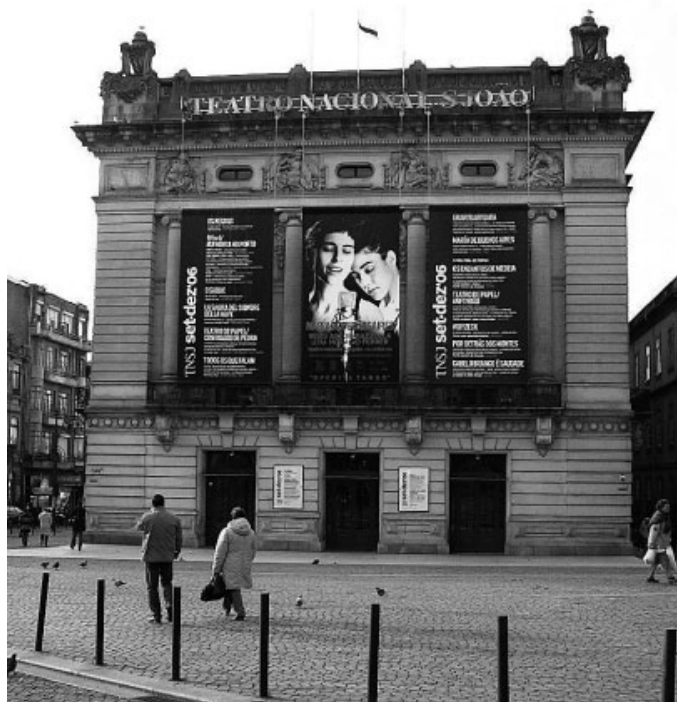

de colectivo espiritual sensivel e laico, e pugna pela alegria na terra, lugar do corpo animado e liberto que é, sem protocolos e regras que não sejam as que são recriadas artisticamente (...). (23-24)

Embora longe de constituir o cerne do seu argumento, Fernando Mora Ramos não deixa de fazer justiça à ideia já registada em 2000 de que "sinal de novo-riquismo é certamente a obsessão generalizada pelo contemporâneo" (Ramos 2000: 9), falando, com reconhecida irrisão, da "arbitrariedade caótica da performatividade 'evenemencial" e da "invenção das 'artes performativas'", a que cedem "alguns 'surfistas' do que está a dar" $(24-25,26)$.

Todo o restante ensaio dedica-se, de forma mais sistemática, ao esboço de um "plano de ordenamento enérgico e racional de futuro" (23), distribuido por treze pontos - "Teatro e mercado", "Da criação", "Gangrena e urgências", "No coração do sistema, um mecanismo propulsor", "Companhias nacionais/centros de estágio", "Companhias de incidência local, nacional e autarquias", "Internacionalização", "A língua", "Em prol dos clássicos", "Com - contra - os média em prol da cultura", "O teatro para os mais pequenos", "Centros de dramaturgia, escrita" e "Uma geografia e uma demografia" - um conjunto substancial de páginas (quase quarenta) que, sem abandonar a lucidez e a contundência que caracteriza todo o texto (caracteristicas, aliás, extensíveis aos outros três autores), tem a vantagem de propor medidas efectivas, numa lógica que, sugestivamente, o autor apresenta como "expansiva" - em oposição à de "resistência" - e apostada na indispensável "longevidade" (38). É um programa amplo, tão claro na demonstração daquilo para que não devem servir os "dinheiros públicos" (35), como na abordagem de questões ligadas aos domínios da formação, da escrita, da pesquisa, do próprio equilíbrio territorial, da internacionalização, da língua, da relação com os meios de comunicação social, do teatro para a infância e juventude, etc.

À afirmação dolorosa e inabalável de que "[u]ma parte do teatro português tem gangrena, está morta" (34) corresponde a mais eufórica admissão da "enorme vitalidade de muito do teatro que se faz" (36), isto é, o reconhecimento de que existe "teatro e tradição teatral recente (...) capaz 


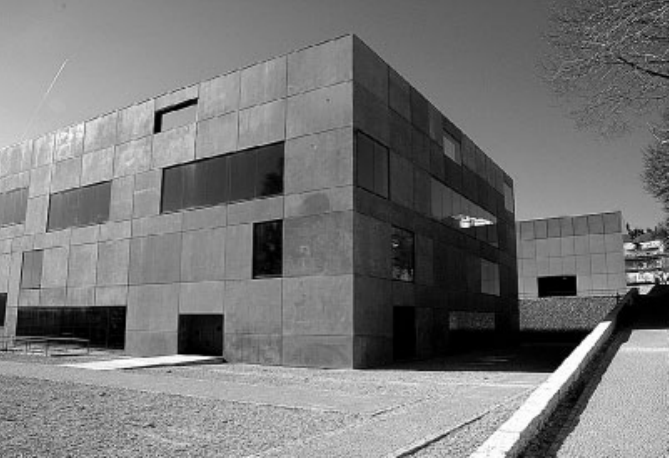

de se constituir em elemento propulsor de outra realidade" (36), aquilo que o autor tantas vezes apresenta como uma "visão alternativa" ou um "mundo alternativo" (27).

É pena que o texto que se segue neste livro não seja o de José Luís Ferreira que, sob o título mais enigmático de "Não é fácil...", apresenta uma estimulante reflexão, no contexto da qual não só se distingue com clareza a "actividade artística nuclear" daquilo a que o "politiquês" prefere chamar as "indústrias culturais", como se voltam a tecer importantes considerações sobre as dimensões de "utilidade social" e de "experimentação formal" (26) do teatro: "Aquilo que se discute é, portanto, a inclusão das politicas culturais no menu das políticas públicas enquanto instrumento de cidadania e civilização" (118). E se este ensaio ganharia por se seguir imediatamente ao de Fernando Mora Ramos é porque ele exibe igualmente uma dimensão mais lata e abrangente nas suas considerações, particularmente na penetrante contextualização da nossa realidade local e no tão revelador quanto perturbador estudo comparativo que ocupa a terceira e última parte deste texto de José Luís Ferreira. Para lá da mesma denúncia da "ausência de investimento em políticas de longo prazo" - a "longevidade" que se identificou no ensaio de Fernando Mora Ramos -, fala-se dos poderes públicos, naturalmente, mas também dos teatros nacionais $\mathrm{e}_{\text {, ainda que com }}$ discrição, da experiência do Teatro Nacional São João, da situação dos Teatros Municipais - "espécie de brindes oferecidos às autarquias sem que porém tivesse sido contratualizada a sua missão e a respectiva partilha de responsabilidade entre Estado central e local" (124-5) e do "sector privado da criação artística" - "uma história feita de persistência, coragem pessoal, aventura estética, mas também de percursos erráticos, dificuldades extremas na estruturação de projectos a longo prazo, confinamento de métodos e práticas..." (126).

Um dos traços mais positivos e mais meritórios de todos os ensaios deste livro - uma quase directiva programática transversal a todos os discursos - é a forma directa e desassombrada como se abordam aspectos concretos da nossa realidade política na área da cultura, exemplarmente ilustrada no passo em que José Luis Ferreira afirma, a propósito dos sucessores de Manuel Maria Carrilho na pasta da cultura:

Cada um deles (...) seguiu um de dois caminhos: ou o desenvolvimento de um projecto excessivamente personalizado, cumprindo (ou, felizmente, não) um sonho plástico de modelação da realidade; ou então uma espécie de comissariado politico tendente quase exclusivamente à menorização do estatuto e da função do Ministério e à aceitação passiva do discurso da crise. (129)

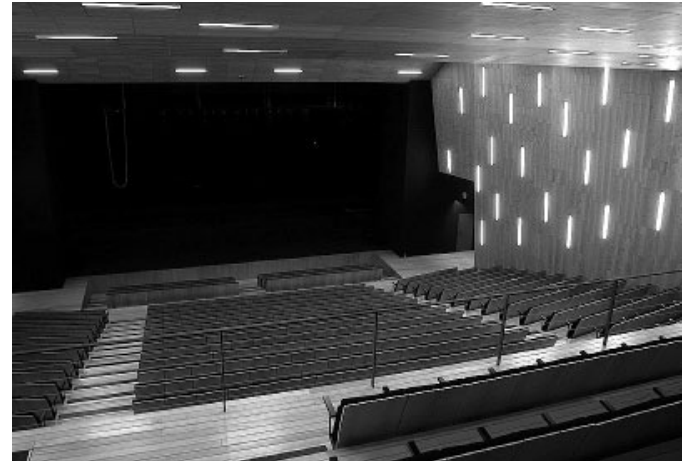

Teatro Municipal da Guarda, fot. Armando Neves.

Grande Auditório do Teatro Municipal da Guarda, fot. Armando Neves.

Tirando partido da sua vasta experiência internacional, na coordenação do Departamento de Relações Internacionais do TNSJ e, por consequência, na participação em importantes fóruns europeus e na organização desses mesmos fóruns entre nós, como aconteceu com o encontro "Teatro Europa", em 2007, José Luis Ferreira dedica a última parte da sua reflexão a um "estudo comparado", no qual convoca com pormenor as realidades dos sistemas francês, espanhol e finlandês, para poder concluir que não será "portanto por falta de exemplos que os sucessivos governos portugueses não encontram os caminhos de uma definição eficaz dos caminhos a percorrer e dos meios a envolver" (141).

Os outros dois ensaios, de Américo Rodrigues e de Manuel Portela, caracterizam-se pelo seu enfoque mais particular, mas não menos modelar na revelação de alguns problemas estruturais e outros atavismos mais ou menos constrangedores da presente realidade do sistema teatral português. (E por isso dizia atrás que, em minha opinião, o livro poderia ter ganho com uma outra organização, em que fosse mais claro o caminho do geral para o particular.) Sob o título bem explícito de "A descentralização. A rede. As políticas culturais", Américo Rodrigues - animador cultural, escritor, criador com interesses nas áreas da poesia sonora e da experimentação vocal e, neste contexto sobretudo, programador experimentado que desde 2005 dirige o Teatro Municipal da Guarda - assina o texto talvez mais desassombrado - no conteúdo e no próprio tom e registo adoptados - sobre o "desanimador" panorama da descentralização cultural no nosso país:

São necessárias (...) politicas continuadas de afirmação e desenvolvimento de centros criativos por todo o pais. Temos assistido é, exactamente, o contrário: existem equipamentos espalhados pelo pais, mas escasseiam politicas claras que realizem na plenitude a descentralização cultural. (68)

É de uma nova realidade que Américo Rodrigues nos fala - uma realidade que estaria por completo ausente da proposta de "identificação" do teatro português ambicionada por Fernando Mora Ramos em 2000, quando ainda podia falar, com algum ressentimento, dos "'deuses' programadores" (Ramos 2000: 8) -, de um território nacional no qual "floresceram como cogumelos (venenosos?) Teatros e Cine-Teatros de média e grande dimensão", que rapidamente deram origem a uma "Rede Nacional de Teatros e Cine-Teatros", muito embora o "nome "Rede" (...) não correspond[a] a nenhuma prática e, muito menos, a nenhuma política" $(68,69)$.

Desassombradamente, repita-se, Américo Rodrigues insiste: 
Cartaz do ciclo

Beckett no TAGV

Teatro Académico $\mathrm{G}$ Vicente, 15 a 25 de Maio de 2006, desenho gráfico

de Joana Monteiro

Cartaz do ciclo

Blake no TAGV

Teatro Académico Gil

Vicente, 6 a 28 de

Novembro de 2007,

desenho gráfico

de Joana Monteiro.
Diga-se desde já: a "Rede Nacional de Teatros e Cine-Teatros" não existe. É uma ficção alimentada por quem não quer assumir, de uma vez, por todas, as suas responsabilidades. A referência à putativa Rede fica bem em todos os discursos oficiais mas não passa de uma manipulação a que urge pôr fim. (69)

0 autor desenrola uma espécie de lista de horrores, relativos a diversos aspectos, a saber: o modo como foi contratualizada a construção ou reconstrução destes espaços - "quase nada foi exigido às autarquias concorrentes à criação de um Teatro, em relação ao futuro: programação, gestão, manutenção, envolvimento da comunidade" (70) -, à própria projecção arquitectónica desses espaços, eivados, muitos, de "fragilidades estruturais" e "debilidades funcionais" (71), aos processos de nomeação dos seus responsáveis - "como não hà directores artísticos (...) a 'programação' do espaço fica à responsabilidade de um vereador da cultura, cujos únicos critérios são saber se o espaço está disponivel e se o 'artista' é conhecido da televisão" -, à sua programação - "de uma pobreza confrangedora: sem objectivos, em roda livre, sem qualquer identidade, sem acção pedagógica" - e à ausência de mecanismos de apoio para o seu regular funcionamento enquanto instrumentos que prestam um "serviço público". Para além de não haver uniformidade nos modelos de gestão, não há quaisquer plataformas de encontro entre programadores e directores artísticos destes teatros, em resumo, como a cidade do Porto muito bem sabe, não há quaisquer mecanismos susceptíveis de evitar que um destes teatros se transforme num "simples salão de festas, à mercê de vontades propagandísticas baseadas no entretenimento do povo" (85).

Depois de uma referência à Red de Teatros de Castilla y Léon, Américo Rodrigues refere-se em mais pormenor à experiência bem mais positiva do Teatro Municipal da Guarda, abordando múltiplos aspectos e alternativas ligados à gestão e programação destes espaços que alteraram "profundamente a paisagem cultural do nosso pais" (97-98), para concluir, com o mesmo tom de urgência que atravessa todas estas quatro reflexões: "Do Ministério da Cultura e das autarquias esperamos que se entendam e que assumam as suas responsabilidades numa efectiva e qualificada descentralização cultural" (110).

0 ensaio de Manuel Portela, personalidade ligada à Universidade de Coimbra que durante três temporadas apenas foi director do Teatro Académico Gil Vicente intitulado "TAGV 2005-2008: Uma Experiência Interrompida", tem como principal foco um equipamento com a particularidade, justamente, de ser um teatro universitário, com uma existência e uma história bem
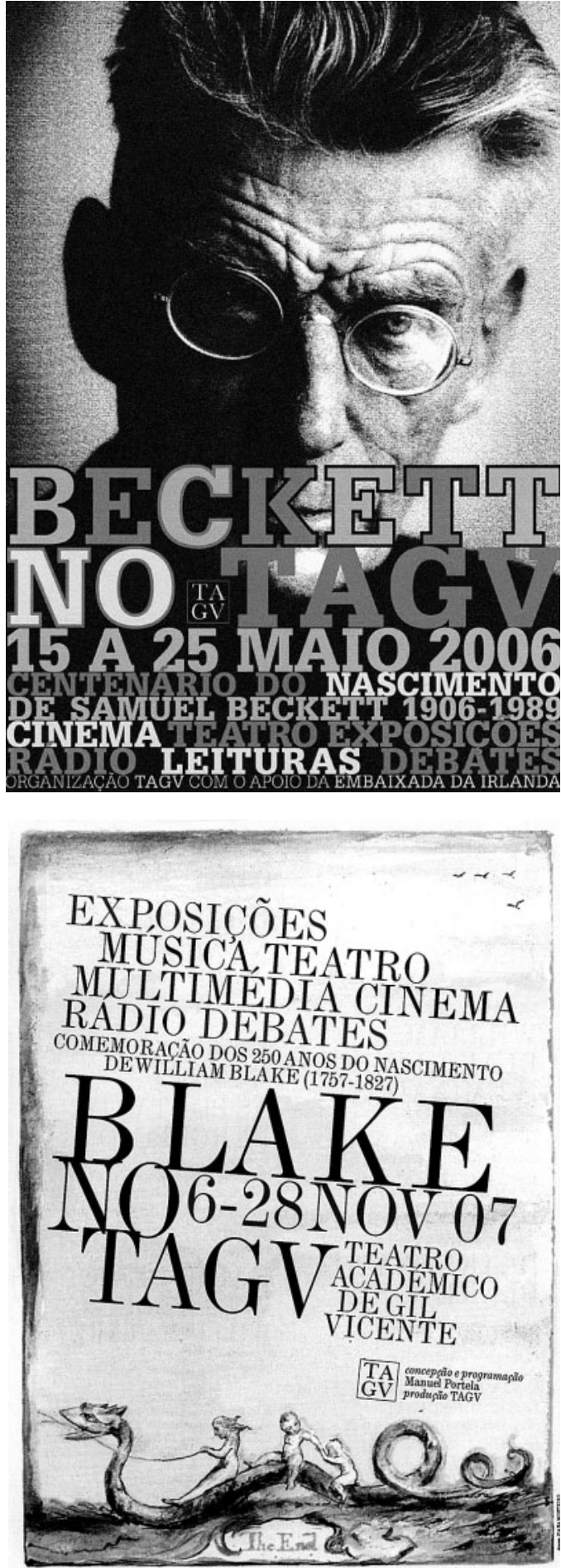

anterior à dos Teatros Municipais, mas com alguns problemas tristemente semelhantes. Este é o texto mais palimpséstico, devido ao facto de o seu autor - de um modo, curiosamente, semelhante ao que adoptou Isabel Alves Costa para o seu relato muito pessoal da experiência do Rivoli Teatro Municipal até 2006 (Costa 2008) - alternar a sua reflexão mais actual, destinada a esta publicação com a recuperação de diversos textos programáticos oportunamente elaborados para os materiais das actividades daquele teatro entre 2005 e 2008. Embora se assuma justamente como "um exercício de reflexão sobre gestão artística" (149), é um ensaio profundamente 


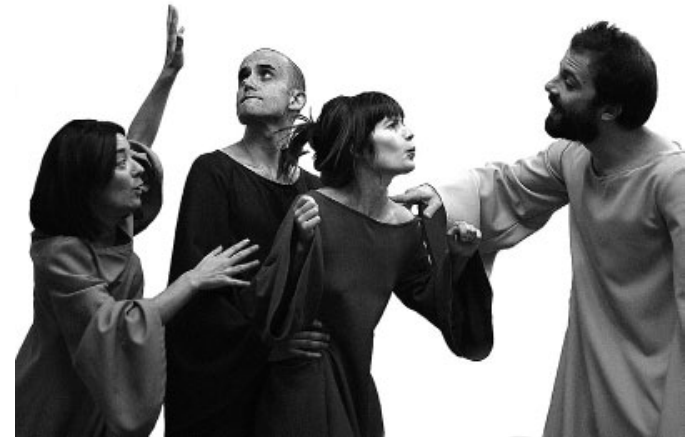

informado por um conhecimento teórico e, por vezes, quase filosófico da cultura, o que o leva, por exemplo, a afirmar, quando reflecte sobre "o problema da coerência interna da programação quando pensada no contexto da reprodução cultural da sociedade", que:

De acordo com esta perspectiva, a lógica de programação não pode ser justificável apenas internamente, isto é, sem referência ao conjunto de factores de indole exógena que determinam - de forma aleatória, imprevisivel, incontrolável e inconsciente - a forma e a função da programação. Aquilo que parece dificil de articular conceptualmente é a relação entre uma lógica interna, programática e auto-justificada, e uma lógica externa, não programável nem justificável. (...) Uma reflexão consequente sobre a função social da gestão artística implica portanto recontextualizar a intencionalidade programável (isto é, a intencionalidade enquanto estruturação de conteúdos e formas artisticas de acordo com critérios explicitáveis) não apenas na esfera de produção e recepção artística, mas na esfera mais lata dos modos

de reprodução social, económica e politica da sociedade. $(156,158-9)$

Manuel Portela discute, com clareza, não só os processos de escolha de muitos dos programadores "sem uma avaliação pública dos seus méritos absolutos e sem um projecto de gestão artística e de programação concreto" (162) -, mas também aspectos mais vastos da nossa realidade actual, como "o incremento geral da produção artística e cultural", a "aceleração dos ciclos de produção e recepção", sugerindo, por exemplo, que a "debilidade da educação artística da sociedade é um sintoma da desarticulação persistente entre política cultural e política educativa" (163).

Concentrando-se no caso concreto do Teatro Académico Gil Vicente, o autor demora-se no projecto delineado e posto em prática nas três temporadas entre 2005 e 2008, centrado numa tentativa de "redefinição do TAGV como teatro público universitário". Recorrendo inclusive a alguns intertextos - mais do que extratextos - iconográficos, como os cartazes dos ciclos dedicados a Samuel Beckett ou a William Blake e algumas fotografias de espectáculos, Manuel Portela tenta dar conta de um "modelo de programação universitária que alia programação e criação, criação artística e investigação científica, missão universitária e missão pública, ligando entre si as escalas local, nacional e internacional" (176). Nos domínios vários do teatro, do cinema, da música, do livro e da leitura, das exposições, da organização do trabalho, da comunicação com o público e das relações inter-institucionais, é todo um projecto sólido cuja descontinuação - ou "fracasso" - parece ter-se ficado a dever, uma vez mais, a decisões políticas indiferentes e

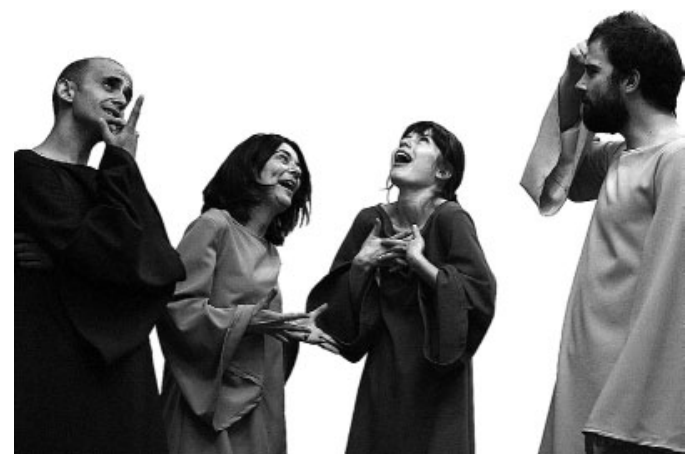

Ensaios de

Uma ilha na lua

a partir de William Blake,

enc. José Geraldo,

Camaleão / Teatro

Académico Gil Vicente,

2007,

fot. Francisca Moreira insensiveis à coerência e alcance de uma lógica programática. Como conclui Manuel Portela, e como conclui este livro, que "isso aconteça sem que a comunidade servida possa, de algum modo, intervir no processo diz muito acerca da debilidade do espaço público e da inanidade da democracia, dentro e fora da universidade" (204).

Talvez não planeado, este é um modo poderoso e inquietante de terminar uma obra colectiva que, mais do que entrar certamente para a história da reflexão sobre teatro em Portugal - pela originalidade, seriedade, alcance e profundidade das reflexões registadas -, deveria funcionar, e esse será certamente o desejo dos seus autores, como despoletador de uma nova dinâmica de responsabilização, a nível da decisão política, sem dúvida, mas também a um nível mais alargado da não menos política consciência e participação colectiva. Trata-se, na realidade, de um conjunto de quatro ensaios que informam, tanto quanto inquietam, qualquer leitor, e muito em particular quando esse leitor se reconhece, de algum modo, como parte activa de um sistema teatral a cuja dinâmica de futuro não poderá nunca ser estranho.

P.S. Infelizmente, a leitura das perturbadoras declarações da actual responsável pela pasta da cultura do governo português, que se atreveu a falar na necessidade de combater o "sistema da subsídiodependência" (Público, 24 de Março de 2010), confirmanos que estas lúcidas reflexões não tiveram ainda o impacto desejado...

\section{Referências bibliográficas}

COSTA, Isabel Alves (2008), Rivoli: 1989-2006, Porto, Edições Afrontamento. RAMOS, Fernando Mora (1998), "Editorial", Teatro escrito(s): Revista de ensaio e ficção, n. 1: Para que é que serve o teatro?, Lisboa, IPAE e Livros Cotovia, pp. 9-13.

--(1999), "Editorial", Teatro escrito(s): Revista de ensaio e ficção, n. 1 : Para que é que serve o teatro?, n. 2 : Está tudo bem com o teatro em Portugal?, Lisboa, IPAE e Livros Cotovia, pp. 7-12.

--(2000), "Editorial", Teatro escrito(s): Revista de ensaio e ficção, Lisboa, IPAE e Livros Cotovia, n. 3 : Teatro português: 'Pera onde is?'", pp. 7-12. 